thiếu kẽm ở nhóm can thiêp so với nhóm chứng. Lời cám ơn: Nghiên cứu thuộc đề tài cấp Viện được hỗ trợ bởi công ty cổ phần sữa Nutifood.

\section{TÀI LIÊU THAM KHẢO}

1. Krebs NF, Hambidge KM. Zinc deficiency in infants and children: a review of its complex and synergistic interactions. Paediatrics and International Child Health. 2014; 34: 279-288.

2. Hoàng Văn Phương, Trân Thúy Nga và CS. Hiệu quả sử dụng hạt nêm, dầu ăn bổ sung vi chất tới tình trang vitamin A và kẽm ở trẻ 36-59 tháng tuổi suy dinh dưỡng và nguy cơ suy dinh dưỡng thấp còi. Tap chí Y hoc Viêt Nam, tâp 472. 2018; 119-128.

3. WHO- UNICEF. Vitamin and mineral deficiencies technical situattion analysis. Global Allliance for Improve Nutrition. 2006.

4. Lê Danh Tuyên, Lê Bạch Mai. Nhu câu Dinh dưỡng khuyến nghị cho người Việt Nam. Nhà xuất bản Y học, 2016.
5. Mandlik R, Khadilkar A et al. Response of Serum 25(OH)D to Vitamin D and Calcium supplementation in School-Children from a SemiRural setting in India. J Steroid Biochem Mol Biol. 2017; (17): 30367-9.

6. Nguyễn Xuân Ninh và CS. Hiệu quả của bánh bích quy có bổ sung Ergostrerol giàu vitamin D2 đến tình trạng dinh dưỡng và một số chỉ tiêu hóa sinh trên học sinh tiểu học. Tạp chí Dinh dưỡng và Thực phẩm. 2014; 10(4): 132-140.

7. Phạm Văn Hoan, Nguyến Thanh Hà. Sử dụng Sprinkles trong phòng chống thiếu vi chất dinh dưỡng trẻ em. Tạp chí Dinh dưỡng \& Thực phẩm. 2010; Tâp 6, số 2: 1-9.

8. Trân Thúy $\mathbf{N g a}$. Hiệu quả bổ sung sũa "Vinamilk $100 \%$ sữa tươi - học đường", sữa "Vinamilk ADM GOLD - học đường" có bố sung vi chất đối với tình trạng dinh dưỡng và vi chất dinh dưỡng ở trẻ $7-10$ tuổi sau 6 tháng can thiêp. Báo cáo nghiệm thu kết quả nghiên cứu đề tài cấp Viện Dinh dưỡng, 2017.

\title{
KẾT QUẢ SỬ DỤNG ỐNG NỐI CÓ VAN TAOO HÌNH ĐƯờNG RA THẤT PHẢI TRÊN BỆNH NHÂN TIM BẨM SINH TẠI BỆNH VIỆN NHI TRUNG ƯO'NG
}

\author{
Trần Quang Vịnh ${ }^{1}$, Đoàn Quốc Hưng ${ }^{2}$, Nguyễn Lý Thịnh Trường ${ }^{1}$
}

\section{TÓM TẮT}

Mục đích: Báo cáo kết quả sớm sau phẫu thuâtt (PT) sử dụng ống nối có van tạo hình đường ra thất phải trên bệnh nhân tim bẩm sinh tại Bệnh viện Nhi Trung ương năm 2020. Phương pháp: Năm 2020, đã có 1200 ca PT tim mở được tiến hành tại Bệnh viện Nhi Trung ương trong đó có 70 bệnh nhân $(5,8 \%)$ tim bẩm sinh được sử dụng ống nối có van tạo hình đường ra thất phải. Chúng tôi tiến hành nghiên cứu cắt ngang, mô tả kết quả sớm sau PT sử dụng ống nối có van trên nhóm bệnh nhân này. Kết quả: Có 44 nam $(62,9 \%)$ và 26 nữ $(37,1 \%)$. Trong đó $\mathrm{PT}$ sửa toàn bộ thân chung động mạch $(15,7 \%)$, PT sửa teo và hep ĐMP $(60 \%)$, PT Ross $(5,7 \%)$, PT thay van phổi sau PT sửa toàn bộ trước đó $(18,6 \%)$. Ống nối được sử dụng là Contegra $(91,4 \%)$, Hancock $(5,7 \%)$, Homograft ĐMP $(2,9 \%)$ với kích thước trung bình 16 $(9-25)$ mm. Tại thời điểm PT, tuổi trung bình là 24,4 $\pm 33,7$ [1 - 171] tháng và cân nặng trung bình là 9,2 $\pm 6,4[2,6-41,0] \mathrm{kg}$. Thời gian chạy máy và thời gian cặp chủ trung bình lần lướt là $155 \pm 51$ [72-381] phút và $81 \pm 47$ [21-209] phút.Tưviong có $5 \mathrm{BN}(7,1 \%): 4$ $\mathrm{BN}$ tử vong trong thời gian nằm viện, $1 \mathrm{BN}$ tử vong sau khi ra viện 1 tháng do viêm phổi. Các BN còn lại đều được theo dõi tối thiểu 3 tháng sau mổ. Kết quả

\footnotetext{
${ }^{1}$ Trung tâm Tim mạch trẻ em-Bệnh viện Nhi Trung ương 2Trường Đại học Y Hà Nội

Chịu trách nhiệm chính: Nguyễn Lý Thịnh Trường Email: nlttruong@gmail.com

Ngày nhận bài: 13.4.2021

Ngày phản biện khoa học: 25.5 .2021

Ngày duyệt bài: 14.6.2021
}

siêu âm sau mổ thây tỉ lê hở phổi trung bình nhe $(15,7 \%)$, không hở hoặc hở rất nhe $(84,3 \%)$. Chênh áp trung bình qua ống nối $10 \pm 8$ [1-35]mmHg. Kết luận: Sử dụng ống nối có van tạo hình đường ra thất phải trên các bệnh nhân tim bẩm sinh phức tap tai Bệnh viện Nhi Trung Ương là khả thi. Việc theo dối lâu dài là hoàn toàn cân thiết.

Tứ khoá: Thân chung động mạch, Teo phổi, Hẹp phổi, Ống nối có van.

\section{SUMMARY \\ EARLY OUTCOMES OF VALVED CONDUIT FOR RIGHT VENTRICULAR OUTFLOW TRACT RECONSTRUCTION IN CONGENITAL HEART DEFECTS PATIENTSAT NATIONAL CHILDREN'S HOSPITAL}

Objectives: To Report the early outcomes of valved conduit for right ventricular outflow tract reconstruction in congeniatl heart defects at National Children's Hospital in 2020. Methods: In 2020, 1200 cases of open-heart surgery were conducted at our hospital, in which 70 patients $(5.8 \%)$ are using the valved conduit for reconstruct the right ventricular outflow tract. We conducted a cross-sectional study, describing the early postoperative resultsin this group of patients. Results: There were 44 male $(62.9 \%)$ and 26 female (37.1\%), in which Truncus (15.7\%), Pulmonary atresia or stenosis (60\%) Ross's procedure (5.7\%),Pulmonary valve replacement $(18.6 \%)$. The conduits areContegra (91.4\%), Hancock (5.7\%), Homograft DMP (2.9\%) with an average size of 16 (925) $\mathrm{mm}$. At the time of surgery, the mean age was $24.4 \pm 33.7[1$ - 171] months and the meanweight was $9.2 \pm 6.4[2.6-41.0] \mathrm{kg}$. The mean bypass time 
and cross-clamped time were $155 \pm 51$ [72 - 381] minutes and $81 \pm 47$ [21 - 209] minutes, respectively. Early death has 5 patients (7.1\%): 4 patients died during hospital stay, 1 patient died 1 month after dischargedue to pneumonia. The remaining patients are monitored for at least 3 months after surgery. The echocardiography at last check-up showed that the average rate of mild to moderate pulmonary insufficency $(15.7 \%)$, No PI $(84.3 \%)$. Mean pressure gradient across the conduitwas $10 \pm 8[1-35] \mathrm{mmHg}$. Conclusions: Using a valved conduit to shape the right ventricular outflow tract in complicated congenital heart defect patients at National Children's Hospital is feasible. Long term follow-up is absolutely in need.

Keywords: Truncus Arteriosus, Pulmonary Atresia, Pulmonary Stenosis, Valved conduit

\section{I. ĐĂT VẤN ĐỀ}

Tạo hình phần nối thất phải và động mạch phổi làkĩ năng quan trọng của bất cứ phẫu thuật viên tim bẩm sinh nào. Tiêu chuẩn vàng trong phẫu thuật ống nối thất phải - động mạch phổi là sử dụng ống nối có van tự thân được bảo quản trong huyết tương (cryopreserved homograft) [1]. Tuy nhiên, ở trẻ em, kích thước cơ thể nhỏ thường không phù hợp với những ống nối homograft kích thước lớn nên còn nhiều hạn chế trong việc sử dụng homograft. Trong khi đó việc sử dụng ống nối nhân tạo như Contegra (từ tînh mạch cảnh trong bò) hay Hancock (từ màng tim lợn) có kích thước linh hoạt (12 $22 \mathrm{~mm}$ ) đã giúp cho các phẫu thuật có chỉ đinh tạo hình phẩn nối thất phải - động mạch phổi ở trẻ nhỏlà khả thi [2], [3], [4]. Trong năm 2020, tại Bệnh viện Nhi Trung Ương đã có 1200 ca PT tim mở được tiến hành trong đó có 70 bệnh nhân (chiếm 5,8\%) được sử dụng ống nối có van tạo hình đường ra thất phải. Chúng tôi tiến hành nghiên cứu cắt ngang, mô tả kết quả sớm sau PT sử dụng ống nối có van trên nhóm bệnh nhân này.

\section{II. ĐốI TƯợNG VÀ PHƯƠNG PHÁP NGHIÊN CỨU}

2.1 Đối tượng nghiên cứu. Nghiên cứu bao gồm 70 bệnh nhân (44 nam, 26 nữ) được phẫu thuật tạo hình đường ra thất phải bằng ống nối có van tại Trung tâm Tim mạch Trẻ em - Bệnh viện Nhi Trung ương trong năm 2020.

2.2 Phương pháp nghiên cứu. Đây là một nghiên cứu hồi cứu, cắt ngang, mô tả loat bệnh với cách lấy mẫu thuận lợi. Các biến liên tục được biểu thị bởi giá trị trung bình, độ lệch chuẩn, giá trị tối đa, tối thiểu. Các biến rời rạc, biến phân loại được biểu thi bởi các giá trị phần trăm. Tử vong sớm sau mổ được đinh nghĩa là tử vong trong vòng 30 ngày sau mổ hoặc trước thời điểm bệnh nhân ra viện sau phẫu thuật sửa toàn bộ. Đánh giá kết quả sau mổ dựa vào tỉ lệ sống sau mổ sửa toàn bộ, kết quả siêu âm tại thời điểm khám lại gần nhất. Số liệu được thu thập và xử lý theo phần mềm SPSS 20.0. Nghiên cứu được thông qua hội đồng đạo đức của Viện Nghiên cứu Sức khoẻ Trẻ em, Bệnh viện Nhi Trung ương; bố mẹ, người giám hộ bệnh nhân được thông tin và đồng ý tham gia nghiên cứu.

2.3 Phấu thuật tạo hình đường ra thất phải bằng ống nối có van. Tất cả các bệnh nhân đều được tiến hành phẫu thuật qua đường mở ngực giữa xương ức. Thiết lâp hệ thống tim phổi nhân tạo giống như các phẩu thuật tim mở thường qui khác. Đối với những bệnh nhân được mổ lại thay van phổi hoặc ống nối, chỉ chạy máy hỗ trợ không cần ngừng tim, chúng tôi chủ động đặt một ca - nuyn vào động mạch chủ và một ca - nuyn tĩnh mạch vào tâm nhĩ phải. Đối với những bệnh nhẩn kèm theo tổn thương trong tim thì chúng tôi đặt một ca - nuyn động mạch chủ và ca - nuyn vào các tĩnh mạch chủ và ngừng tim bằng dung dịch liệt tim xuôi dòng. Những trường hợp sửa toàn bộ bệnh tứ chứng Fallot có hẹp nặng đường ra thất phải hoặc bất thường động mạch vành chạy qua phễu cần dùng ống nối, những trường hợp Teo phổi Thông liên thất sửa toàn bộ thì ngay sau khi thiết lập hệ thống tim phổi nhân tạo, chúng tôi chủ động tạo hình mở rông hai đông mạch phổi bằng màng tim tươi tự thân và nối vào đầu trên của ống nối trước khi cặp động mạch chủ sau đó mới tiến hành sửa chữa các tổn thương trong tim. Đầu trên của ống nối được cắt gần phía trên mép van nhất có thể. Đầu dưới của ống nối được xác định dựa vào đỉnh của đường mở phễu thất phải và cắt chéo lên theo thiết diện của ống nối. Sau khi các tổn thương trong tim đã hoàn thành, tạo hình phần nối kết thúc bằng cách nối đâu dưới của ống nối với đường mở phễu thất phải. Tuỳ theo tình trạng cơtim, chức năng tim, nguy cơ chảy máu sau mổ mà chúng tôi quyết định đóng xương ức ngay hoặc đóng xương ức thì hai khi bệnh nhân sang phòng hồi sức ổn định.

\section{KẾT QUẢ NGHIÊN CỨU VÀ BÀN LUÂN}

Trongnhóm 70 bệnh nhân được nghiển cứu của chúng tôi, bệnh nhân nam chiếm ưu thế $(62,9 \%)$. Triệu chứng lâm sàng nổi bật trước mổ là tình trạng tím $(52,9 \%)$ do đặc điểm tổn thương bệnh lý cần chỉ định phẫu thuật $(51,4 \%$ bệnh nhân được chỉ định phẫu thuật là bệnh nhân tứ chứng Fallot, Teo phổi kèm theo hoặc không kèm theo thông liên thất). Tuổi trung vị lúc phẫu thuật trong nhóm bệnh nhân của chúng 
tôi là 12,5 tháng với số trẻ nhũ nhi (dưới 12 tháng tuổi) là 35 bệnh nhi (chiếm $50 \%$ ) trong đó có 14 trẻ dưới 3 tháng tuổi (chiếm 20\%) và 6 trẻ sơ sinh (chiếm 8,6\%). Tỉ lệ trẻ được phẫu thuật sửa toàn bộ lần đầu chiếm $67,1 \%$. Cho thấy viểc tiến hành phẫu thuật sửa toàn bộcáctổn thương tim phức tạp có chỉ định dùng ống nối có van ở ngay thì đâu cho nhóm trẻ nhỏlà hoàn toàn khả thi.

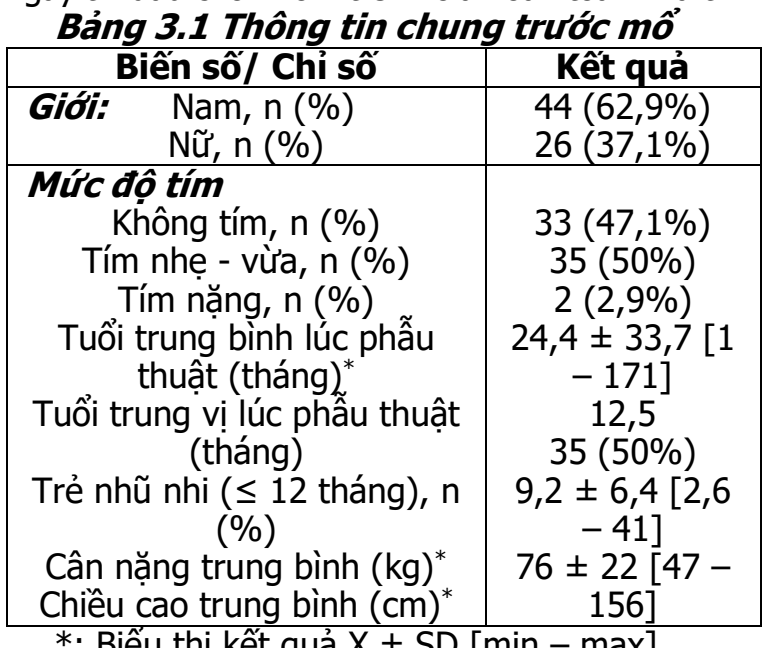

*: Biếu thị kết quả $X \pm S D$ [min - max].

Bảng 3.2: Chỉ định phẫu thuật.

\begin{tabular}{|c|c|c|}
\hline Chấn đoán & $\mathbf{n}$ & $\%$ \\
\hline Thân chung động mạch & 11 & \\
\hline $\begin{array}{l}\text { Teo phổi (kèm theo thông liên } \\
\text { thất hoặc lành vách liên thất) }\end{array}$ & 25 & 35 \\
\hline Tứr chứng Fallot & 11 & 15,7 \\
\hline $\begin{array}{c}\text { Đảo gốc động mach - Thông liên } \\
\text { thất - Hẹp phổi (PT Rastelli) }\end{array}$ & 6 & 8 \\
\hline PT & 4 & 5,7 \\
\hline Thay $v$ & 13 & 8,6 \\
\hline
\end{tabular}

Trong loạt bệnh nhân của chúng tôi, 64 bệnh nhân $(91,4 \%)$ được tạo hình ống nối thất phải động mạch phổi được sử dụng ống nối Contegra (có cấu tạo từ tĩnh mạch cảnh trong của bò), 4 bệnh nhân $(5,7 \%)$ được sử dụng ống nối Hancock, 2 bệnh nhân (2,9\%) được sử dụng Homograft động mạch phối. Mặc dù homograft được coi là tiêu chuẩn vàng đối với phẫu thuât tạo hình phần nối thất phải động mạch phổi nhưng kích thước thường lớn, ngân hàng mô cũng không phải luôn có sẵn [1]. Với đặc điểm cấu tạo của ống Contegra có cấu trúc van của tĩnh mach cảnh trong bò gồm 3 lá van thanh mảnh gần tương đồng với cấu trúc van tim, lớp trong của ống và cấu trúc van có tính liên tục nội mạc. Một số nghiên cứu đã chỉ ra tính an toàn và khả năng thay thế cho Homograft trong tạo hình phần nối thất phải - động mạch phổi của ống nối Contegra, nhất là ở nhóm bệnh nhi nhỏ tuổi [3], [5], [6]. Khi sử dụng, chúng tôi thây thành ống thành tĩnh mạch mềm mại nêncác thao tác cắt và khâu nối ống tương đối dễ dàng và có vẻ ít chảy máu hơn so với khi khâu nối vật liệu tổng hợp như thành của ống nối Hancock. Kích thước của ống Contegracũng đa dạng (từ $12 \mathrm{~mm}$ đến $22 \mathrm{~mm}$ ) nên việc sử dụng ống nối này trong phẫu thuâat tạo hình phần nối thất phải - động mạch phổi ở trẻ nhỏ là khả thi.Chúng tôi cũ̃ng nhận thấy việc sử dụng ống nối này có nhiều điểm dễ dàng và thuận tiện cho các phấu thuật viên, kể cả phẫu thuật viênchưa có quá nhiều kinh nghiệm.

Trong nhóm 70 bênh nhân được phẫu thuật tạo hình phần nối thất phải - động mạch phổi bằng ống nối có van, có 4 bệnh nhân tử vong sớm sau mổ trong thời gian nằm viện. 1 bệnh nhân tử vong sau ra viện 1 tháng do viêm phổi. Tỉ lệ sống sót chung trong nhóm nghiên cứu đạt $92,9 \%$. Breymann và cộng sự [3] báo cáo trong loạt 108 bệnh nhi tim bẩm sinh phức tạp (thân chung động mạch, tứ chứng Fallot, Teo phổi, PT Ross...) được tạo hình phần nối thất phải - động mạch phổi bằng ống nối Contegra có 8 BN $(7,4 \%)$ tử vong sớm và 1 BN tử vong muộn. Tî lệ sống sót chung là $91,7 \%$.

Bảng 3.3 cho thấy thông tin $5 \mathrm{BN}$ tử vong trong nghiên cứu của chúng tôi: 4 BN mắc dị tật thân chung động mạch, 3 BN được phẫu thuật trong giai đoạn sơ sinh, các BN đều có cân nặng thấp $(\leq 3 \mathrm{~kg})$. Nguyên nhân tử vong sau mổ chủ yếu do suy tim và shock nhiễm khuẩn cho thấy phẫu thuật sửa toàn bộ bệnh lý tim bẩm sinh phức tạp và hồi sức hậu phẫu ở giai đoạn sơ sinh, trẻ cân nặng thấp vần là thách thức lớn, cần được cải thiện hơn nữa.

Bảng 3.3: Thông tin bệnh nhân tử vong.

\begin{tabular}{|c|c|c|c|}
\hline Tên/Giới/Tuối/Cân & Ch.đoán & Conduit & Nguyên nhân tử vong \\
\hline $\begin{array}{c}\text { Ng.G.H/Nam/20 } \\
\text { ngày/3,0kg }\end{array}$ & Truncus type I & 10 & $\begin{array}{c}\text { Suy tim ECMO, shock nhiêm khuấn, suy } \\
\text { đa tạng. Tứ vong sau mố } 10 \text { ngày. }\end{array}$ \\
\hline $\begin{array}{c}\text { Le.T.N/Nư//26 } \\
\text { ngày/2,6kg }\end{array}$ & Truncus type II & 9 & $\begin{array}{c}\text { Suy tim, shock nhiêm khuấn. Tứ vong sau } \\
\text { mổ } 9 \text { ngày. }\end{array}$ \\
\hline $\begin{array}{c}\text { Ng.T.N.H/Nữ/30 } \\
\text { ngày/3,0kg }\end{array}$ & Truncus type II & 10 & $\begin{array}{c}\text { Suy tim ECMO không hiếu quả. Tử vong } \\
\text { sau mố } 13 \text { ngày. }\end{array}$ \\
\hline Ng.G.H/Nữ/2 & PA-VSD type I & 12 & Suy tim ECMO, nhiêm trùng nặng. Tứ \\
\hline
\end{tabular}


TẠP CHÍ Y HỌC VIẸTT NAM TẬP 503 - THÁNG 6 - SỐ 2 - 2021

\begin{tabular}{|c|c|c|c|}
\hline tháng/3,0kg & & vong sau mổ 15 ngày. \\
\hline $\begin{array}{c}\text { Ng.A.N/Nữ } / 4 \\
\text { tháng/3,0kg }\end{array}$ & Truncus type II & 12 & $\begin{array}{c}\text { Tử vong sau ra viện 1 tháng do tăng áp } \\
\text { phổi, viêm phổi nặng. }\end{array}$ \\
\hline
\end{tabular}

*: Truncus: thân chung động mạch. PA - VSD: Teo phối - Thông liên thất.

Bảng 3.4. Các thông tîn trong mổ và tình trạng sau mô.

\begin{tabular}{|c|c|c|}
\hline Cácchisố & $\mathbf{n}$ & Kếtquả \\
\hline $\begin{array}{l}\text { Thời gian chayy máy } \\
\text { (phút) }^{*}\end{array}$ & 70 & $\begin{array}{c}155 \pm 51 \\
{[72-381]}\end{array}$ \\
\hline $\begin{array}{l}\text { Thời gian căpp chủ } \\
\text { (phút) }\end{array}$ & 57 & $\begin{array}{c}81 \pm 48 \\
{[21-209]}\end{array}$ \\
\hline $\begin{array}{c}\text { Phâu thuật kèm theo: } \\
\text { Vá thông liên thất }\end{array}$ & 51 & $72,8 \%$ \\
\hline Cắt vách nón phì đại & 32 & $45,7 \%$ \\
\hline Overhaul thất phải & 4 & $5,7 \%$ \\
\hline Cắt bỏ B-T shunt & 10 & $14,3 \%$ \\
\hline Để hở xương ức & 16 & $22,9 \%$ \\
\hline $\begin{array}{l}\text { Thời gian thở máy } \\
\text { (giờ) }^{*}\end{array}$ & 66 & $\begin{array}{c}77,6 \pm 71,4 \\
{[5-408]}\end{array}$ \\
\hline $\begin{array}{c}\text { Thời gian nằm hồi sức } \\
\text { (ngày) }\end{array}$ & 66 & $6 \pm 4[1-29]$ \\
\hline $\begin{array}{c}\text { Thời gian nằm viện } \\
\text { sau mổ (ngày) }\end{array}$ & 66 & $21 \pm 13[7-90]$ \\
\hline
\end{tabular}

*: Biểu thị kết quả $\mathrm{X} \pm \mathrm{SD}[\min -\max ]$. **: Overhaul: mở rộng thất phải

Các chỉ số trong phẫu thuật và các biến chứng quan sát được trong thời gian điêu trị được biểu thị trên bảng 3.4, 3.5.Thời gian chạy máy trung bình là 155 phút, thời gian cặp động mạch chủ trung bình là 81 phút. Ngay sau mổ có 16 BN $(22,9 \%)$ cân để hở ngực và đóng ngực thì hai sau khi sang hồi sức ổn định. Các biến chứng sau mổ quan sát thấy: Ioạn nhịp $10 \mathrm{BN}$ (14,2\%), nhiễm trùng vết mổ 2 BN $(2,8 \%)$, nhiểm trùng hô hấp $5 \mathrm{BN}(7,1 \%)$, nhiễm khuẩn huyết $5 \mathrm{BN}$ $(7,1 \%)$. Có 4 BN tử vong trong thời gian nằm viện sau mổ. 66 BN còn lại có thời gian thở máy trung bình là 77 giờ. Thời gian nằm hồi sức trung bình là 6 ngày, thời gian nằm viện sau mổ trung bình là 21 ngày. Các bệnh nhân sau ra viện được tư vấn sức khỏe và khám lại theo qui trình của trung tâm.

Bảng 3.5. Biên chứng và tử vong sớm sau mô.

\begin{tabular}{|c|c|}
\hline Biếnchứng & n (\%) \\
\hline Thẩm phân phúc mạc & $7(10 \%)$ \\
\hline ECMO sau mổ & $4(5,7 \%)$ \\
\hline Loạn nhịp cần điều trị thuốc & $5(7,1 \%)$ \\
\hline $\begin{array}{c}\text { Loạn nhịp cân dùng tạo nhịp } \\
\text { tạm thời sau mổ }\end{array}$ & $5(7,1 \%)$ \\
\hline Chảy máu sau mổ & $1(1,4 \%)$ \\
\hline Liệt cơ hoành & $0(0 \%)$ \\
\hline Tràn dịch, tràn khí màng phối & $4(5,7 \%)$ \\
\hline Tràn dịch màng tim & $1(1,4 \%)$ \\
\hline
\end{tabular}

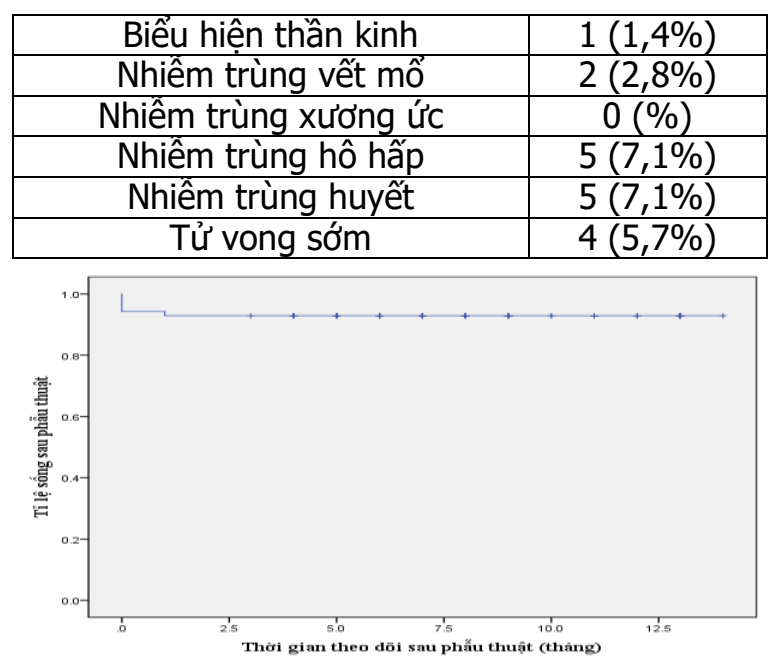

\section{Hình 3.1: Biểu đồ Kaplan - Meier ước tính} tỉ lệ sống sau phẫu thuật.

Theo dõi 65 bệnh nhân sống sau phẫu thuật cho thấy các triệu chứng lâm sàng cải thiện, bệnh nhân ăn được và tăng cân. Trên siêu âm tim gân nhất cho thây chênh áp qua ống nối thấp: $10 \pm 8 \mathrm{mmHg}$. Trong đó có 2 bệnh nhân có chênh áp $30 \mathrm{mmHg}$ và $35 \mathrm{mmHg}$ chưa có chỉ định can thiệp lại, đang được tiếp tục theo dõi, các bệnh nhân còn lại có chênh áp < $20 \mathrm{mmHg}$. Đánh giá hoạt động của van phổi cho thây tỉ lệ không hở hoặc hở rất nhẹ van phổi sau mổ đạt $84,3 \%$, hở trung bình nhẹ là 10,7\%. Theo dõi lâu hơn để đánh giá kết quả dài hạn của ống nối có van tạo hình phân nối thất phải - động mạch phổi là hoàn toàn cân thiết.

\section{KẾT LUẬN}

Từ những kết quả trên cho thấy, việc thực hiện thường qui phẫu thuật sử dụng ống nối có van tạo hình đường ra thất phải trên những bệnh nhân tim bẩm sinh tại Bệnh viện Nhi Trung ương là khả thi và có kết quả tốt. Không có một ống nối lí tưởng nào có thể thay thế được cấu trúc tự nhiên, do vậy một nghiên cứu và theo dõi dài hởn để đánh giá hiệu quả và thời hạn sử dụng của các loại ống nối là hoàn toàn cân thiết.

\section{TÀI LIẸU THAM KHẢO}

1. Boethig D., Goerler H., Westhoff-Bleck M., et al. (2007). Evaluation of 188 consecutive homografts implanted in pulmonary position after 20 years. Eur J Cardio-Thorac Surg Off J Eur Assoc Cardio-Thorac Surg, 32(1), 133-142. 
2. Belli E., Salihoğlu E., Leobon B., et al. (2010). The performance of Hancock porcinevalved Dacron conduit for right ventricular outflow tract reconstruction. Ann Thorac Surg, 89(1), 152-157; discussion 157-158.

3. Breymann T., Boethig D., Goerg R., et al. (2004). The Contegra Bovine Valved Jugular Vein Conduit for Pediatric RVOT Reconstruction:. J Card Surg, 19(5), 426-431.

4. Prior N., Alphonso N., Arnold $P_{\text {., }}$ et al. (2011). Bovine jugular vein valved conduit: Up to
10 years follow-up. J Thorac Cardiovasc Surg, 141(4), 983-987.

5. Morales D.L.S., Braud B.E., Gunter K.S., et al. (2006). Encouraging results for the Contegra conduit in the problematic right ventricle-topulmonary artery connection. J Thorac Cardiovasc Surg, 132(3), 665-671.

6. Carrel T., Berdat P., Pavlovic M., et al. (2002). The bovine jugular vein: a totally integrated valved conduit to repair the right ventricular outflow. J Heart Valve Dis, 11(4), 552-556.

\title{
THỰC TRANG ĐÁNH GIÁ ĐIỂM THƯỜ'NG XUYÊN TẠI TRƯỜ'NG ĐẠI HỌC KỸ THUÂTT Y TẾ HẢI DƯƠNG
}

\author{
Lê Thúy Hường*, Hoàng Thị Thu Hiền* \\ Trương Thị Thu Hương*, Nguyễn Thị Nhung*, Phạm Thị Thắm*
}

\section{TÓM TẮT}

Mục tiêu: 1/Mô tả thực trạng đánh giá điểm thường xuyên tai trường Đại học Kỹ thuât $Y$ tế Hải Dương từ năm 2016-2019. 2/Đề xuất một số giải pháp nâng cao hiệu quả quản lý đánh giá điểm thường xuyên. Phương pháp: nghiên cứu mô tả ngang qua khảo sát ý kiến 144 giảng viên giảng dạy các học phần giai đoạn 2016-2019 tại Trường ĐH Kỹ thuật Y tế Hải Dương. Kết quả: 98.6 \% giảng viên đã phổ biến công khai tỷ lệ, hình thức đánh giá điểm thường xuyên trong đề cương chi tiết; Hình thức đánh giá điểm thường xuyên: bài kiểm tra viết 15 phút: 94.4\%; Kết quả thảo luận nhóm: $56.9 \%$; Trả lời câu hỏi trên lớp: $34.7 \%$; đánh giá kết quả tự học: $23.6 \%$; Số lần kiểm tra thường xuyên: 1 lần: $40.3 \%$; hai lần trở lên: $59.7 \%$. Cách tính điểm thường xuyên giữa các giảng viên: tính điểm trung bình cộng giữa các lần kiểm tra: 88.9\%: chỉ lấy điểm cao nhất: $4.2 \%$; lây điểm bài kiểm tra cuối cùng 4.2\%; lấy điểm ngẫu nhiên: $2.8 \%$; Giảng viên phổ biến đáp án, thang điểm, chữa bài sau khi kiểm tra: $86.1 \%$; trả bài cho SV sau khi kiểm tra: $70.8 \%$; $90.3 \%$ giảng viên cho rằng: cần thiết ban hành quy định đánh giá điểm thường xuyên.

Tứ khóa: kiểm tra, đánh giá, điểm thường xuyên, sinh viên, giảng viên, Đại học Kỹ thuật Y tế Hải Dương

\section{SUMMARY}

THE STATUS OF EVALUATING THE REGULAR SCORE AT HAI DUONG MEDICAL TECHNICAL UNIVERSITY

Objectives: $1 /$ Describe the status of evaluating the regular score at Hai Duong Medical Technical University from 2016-2019. 2/ Propose some solutions to increasing the efficiency of evaluating and managing the regular score at Hai Duong Medical

*Trường Đại học Kỹ thuật Y tế Hải Dương

Chịu trách nhiệm chính: Lê Thúy Hường

Email: thuyhuongdhy@gmai.com

Ngày nhận bài: 12.4.2021

Ngày phản biên khoa họ: 24.5.2021

Ngày duyệt bài: 14.6.2021
Technical University. Methods: a descriptive crosssectional survey to collect opinions of all 144 faculty members of departments directly involved in teaching the courses from 2016 to 2019 at Hai Duong Medical Technical University. Results: $98.6 \%$ of lecturers have publicly disseminated the rate and form of regular score evaluation in the detailed curriculum; Regular score evaluation form: 15-minute written test: 94.4\%; results of group discussion: $56.9 \%$; Answer questions in class: $34.7 \%$; evaluation of self-study results: $23.6 \% ; 41.7 \%$ of lecturers disseminated review content (limited questions) before regular testing; The number of regular checking times: 1 time: $40.3 \%$; twice or more: $59.7 \%$. The way to calculate regular scores among lecturers: calculate the average score between tests: $88.9 \%$ : take only the highest score: $4.2 \%$; take the final test score $4.2 \%$; take the random score: $2.8 \%$; Lecturers disseminate answers, grading scales, and correcting papers after the test: $86.1 \%$; return post-testing to students: $70.8 \% ; 90.3 \%$ of lecturers think that it is necessary to issue regulations on how to evaluate regular scores.

\section{I. ĐẶT VẤN ĐỀ}

Hiện nay, đổi mới phương pháp day học là một yêu cầu cấp bách có tính chất đột phá để nâng cao chất lượng dạy học. Đổi mới phương pháp dạy học đòi hỏi phải tiến hành một cách đồng bộ đổi mới từ nội dung chương trình giáo trình, phương pháp dạy học và kiểm tra đánh kết quả dạy học [1]. Kiểm tra đánh giá có vai trò rất lớn trong việc nâng cao chất lượng đào tạo. Kết quả của kiểm tra đánh giá là cơ sở để điều chỉnh hoạt động dạy - học và quản lý giáo dục

Một trong những hình thức kiểm tra, đánh giá kết quả học tâp là kiểm tra thường xuyên, hình thức đánh giá này được xem là đánh giá quá trình học tập vì sự tiến bộ của người học (đánh giá quá trình) bởi đây là hoạt động đánh giá diễn ra trong tiến trình thực hiện hoạt động giảng day môn học nhằm cung cấp thông tin phản hồi cho 